\title{
Responses in Nitrogen Mass and Nitrogen Metabolism of Wild Sugarcane (Saccharum spontaneum L.) Clones to Enhanced UV-B Radiation Under Field Conditions
}

\author{
Yanqun Zu, Yuan Li, Haiyun Wang and Yongmei He \\ Department of Ecological Environment, College of Resources and Environment, \\ Yunnan Agricultural University, Kunming 650201, P.R. China
}

Received 2013-09-02; Revised 2013-12-11; Accepted 2014-01-07

\begin{abstract}
Field experiments were conducted to evaluate effects of enhanced UV-B radiation (280-315 nm) on intraspecific responses in nitrogen mass and nitrogen metabolism of six wild sugarcane (Saccharum spontaneum L.) clones. The clones were collected from original sites with different altitudes (4-1780 m above sea-level) and latitudes $\left(18-38^{\circ} \mathrm{N}\right)$. The supplemental UV-B radiation was $5.00 \mathrm{~kJ} \cdot \mathrm{m}^{-2}$, simulating a depletion of $20 \%$ stratospheric ozone. Out of the six tested wild sugarcane clones, available Nitrogen (N) contents in soil and $\mathrm{N}$ contents in leaves of four wild sugarcane clones decreased significantly. Leaf biomass and leaf $\mathrm{N}$ mass of six wild sugarcane clones significantly increased. UV-B radiation significantly decreased $\mathrm{N}$ contents and increased biomass and $\mathrm{N}$ mass in stems of six wild sugarcane clones. Contents of free amino acid of two wild sugarcane clones (92-11 and 92-36) significantly decreased, whilst that of clones 83-193 and II91-5 significantly increased. Total protein contents of three wild sugarcane clones significantly decreased, whilst that of clone 90-15 significantly increased. Nitrate reductase activities of two clones (92-11 and 90-15) significantly decreased, whilst that of four clones significantly increased. Glutamine synthetase activities of two clones (92-11 and 90-15) significantly increased, while that of clones 83-193 significantly decreased. UV-B radiation might change stem biomass, resulting in changes in $\mathrm{N}$ mass in stem and leaves. Results indicate that intraspecific responses in N mass and N metabolism of six wild sugarcane (S. spontaneum) clones differing in UV sensitivity to enhanced UV-B radiation exist under field conditions.
\end{abstract}

Keywords: Saccharum spontaneum L., UV-B Radiation, N Mass, Nitrate Reductase, Glutamine Synthetase, Intraspecific Responses

\section{INTRODUCTION}

Increases in UV-B radiation due to stratospheric ozone depletion have been estimated to continue until the 2050 s due to the production of ozone destroying chemicals and released compounds of chlorine and bromine (Weatherhead et al., 2005). Differences in UV$\mathrm{B}$ radiation are not only the outcome of changes in the ozone layer and altitude, latitude and atmospheric aerosols strongly influence the amount of UVB that reaches the surface. In addition, both direct and indirect effects on UV-B play important roles (Watanabe et al., 2012). Over the past three decades, studies have focused on effects of enhanced UV-B radiation on plants and indicated that UV-B radiation can affect plant growth, morphological, physiological and biochemical changes and modify biomass production and reproductive processes (Sullivan, 2005).

Corresponding Author: Yuan Li, Department of Ecological Environment, College of Resources and Environment, Yunnan Agricultural University, Kunming 650201, P.R. China Tel: +86 87165227550 Fax: +86 87165227550 
The effects of UV-B are clone-, cultivar- and speciesspecific ( $\mathrm{Zu}$ et al., 2005; Sullivan, 2005). The tolerance of $\mathrm{C}_{4}$ plants to UV-B was higher than that of $\mathrm{C}_{3}$ (Kakani et al., 2008). Wild plant sensitivity to UVradiation may be related to both ambient UV-B radiation and plant (Albert et al., 2008; Beckmann et al., 2012). Wild sugarcane (S. spontaneum) is one of the wild parent species of cultivated sugarcane ( $S$. officinarum) and could be used for fodder production in tropical and subtropical regions with higher UV-B radiation levels (Li et al., 2006a). The effects of enhanced UV-B radiation on growth, physiology, ion leakage and flavonoid contents of wild sugarcane have been studied (Li et al., 2006a; 2006b; 2008a). Few field studies have been completed on effects of enhanced UV-B radiation on nutrient accumulation and nutrient metabolism of wild sugarcane and intraspecific variations.

Studies on the effects of UV radiation on the $\mathrm{N}$ metabolism of plants has received increased attention (Correia et al., 2005; 2012). UV-B radiation may affect $\mathrm{N}$ cycling in ecosystems by decreasing mobilization of $\mathrm{N}$ into biomass, photosynthesis, the decomposition rate of litter and the $\mathrm{N}$ concentration of plants (Moody et al., 2001; Wu et al., 2011). Moreover, reports about intraspecific responses in $\mathrm{N}$ metabolism of plants to enhanced ultraviolet-B radiation under field conditions are limited. Nitrate reductase is a key enzyme of $\mathrm{N}$ metabolism, which converts nitrate into nitrite on the metabolic pathway leading to the formation of amino acids (Canovas et al., 2007). In wild sugarcane, both roots and foliage participated in $\mathrm{NO}_{3}^{-}$reduction (Krywult et al., 2008). Nitrate reductase activity in plants may also depend on temperature, water conditions, light intensity and UV radiation (Niu et al., 2007; Krywult et al., 2008). Nitrate reductase decreased in response to UV-B in both leaf and root tissue of barley plants, whereas glutamine synthetase was affected only in the root (Ghisi et al., 2002). Glutamine synthetase in leaves and roots is a key enzyme in the route of incorporation of inorganic $\mathrm{N}$ into organic compounds (Miflin and Lea, 1980). Effects of enhanced UV-B radiation on activities of nitrate reductase and glutamine synthetase lead to changes in free animo acid, total protein contents and $\mathrm{N}$ assimilation in leaves and roots, depending on photosynthetic functionality and root growth (Ghisi et al., 2002).

Wild sugarcane ( $S$. spontaneum) is a close wild relative of cultivated sugarcane. Wild sugarcane has an important role in sugarcane breeding. All sugarcane hybrids contain genetic materials from this wild species. The within-species variation and mechanism in response to UV-B radiation of wild sugarcane have been investigated for plant growth, plant height, morphology (Zu et al., 2007; Li et al., 2008b), physiology (Li et al., 2008b), flavonoid content (Li et al., 2006b), cell membrane permeability (Li et al., 2006a), brix (Li et al., 2007), rhizosphere microbial community ( $\mathrm{Zu}$ et al., 2005), identification and cloning of molecular markers for UV-B tolerant genes ( $\mathrm{Li}$ et al., 2011) and susceptibility evaluation (Li et al., 2008a). But there is no report on intraspecific responses in $\mathrm{N}$ mass and $\mathrm{N}$ metabolism of wild sugarcane $(S$. spontaneum) clones to enhanced UV-B radiation.

Previously, we proposed the Response Index (RI) criteria to evaluate susceptibility of wild sugarcane clones to UV-B radiation (Li et al., 2008a). In this study, we continued to use the selected clones to undertake further research under field conditions. The aim of this study was: (1) determine if UV-B radiation affects $\mathrm{N}$ mass and $\mathrm{N}$ metabolism, particularly the activities of nitrate reductase and glutamine synthetase of wild sugarcane ( $S$. spontaneum) clones and (2) evaluate intraspecific variations in responses of $\mathrm{N}$ mass and $\mathrm{N}$ metabolism of wild sugarcane (S. spontaneum) clones to UV-B radiation. We hypothesized: (1) enhanced UV-B radiation may affect $\mathrm{N}$ mass and $\mathrm{N}$ metabolism and result in intraspecific responses in $\mathrm{N}$ mass and $\mathrm{N}$ metabolism of wild sugarcane ( $S$. spontaneum) clones and (2) intraspecific responses in $\mathrm{N}$ mass and $\mathrm{N}$ metabolism of wild sugarcane $(S$. spontaneum) clones to UV-B radiation may be related to the ambient UV-B radiation received in the originating region.

\section{MATERIALS AND METHODS}

\subsection{Plant Materials and Growth Condition}

The field experiment was conducted on an upland red soil at Yunnan Agricultural University, Kunming, China. No fertilization was necessary during the season. In our previous experiment, six wild sugarcane (S. spontaneum) clones were chosen for this experiment according to RI from 23 wild sugarcane clones with different UV-B radiation backgrounds (latitude or elevation) (Li et al., 2008a). Six wild sugarcane clones included two tolerant clones (92-11, 90-15), two middle sensitive clones (83-193, 92-36) and two sensitive clones (II91-72, II 91-5) (Table 1).

Seedlings of six wild sugarcane clones were obtained from Institute of Sugarcane of Yunnan Agricultural University and planted at rows spaced 0.4 $\mathrm{m}$ apart at a density of 15 seedlings $\mathrm{m}^{-1}$ in 36 plots of $2 \times 1 \mathrm{~m}$ each on March 14, 2010. The overall experimental design was a randomized complete block with two UV-B treatments and 3 replications. 
Yanqun Zu et al. / American Journal of Environmental Science 9 (6): 446-457, 2013

Table 1. The origin, altitude and latitude of six wild sugarcane (S. Spontaneum) clones

\begin{tabular}{llclr}
\hline Clones & Origin & Altitude $(\mathrm{m})$ & Latitude $\left({ }^{\circ} \mathrm{N}\right)$ & RI \\
\hline $92-11$ & Yacheng, Hainan & 12 & 18 & 297 \\
$90-15$ & Cayu, Tibet & 1460 & 28 & 213 \\
$83-193$ & Yiliang, Yunnan & 1780 & 25 & 89 \\
$92-36$ & Haikou, Hainan & 4 & 20 & -48 \\
III1-72 & Xianyou, Fujian & 30 & 26 & -89 \\
II 91-5 & Chenggu, Shanxi & 500 & 34 & -133 \\
\hline
\end{tabular}

At 45 days after planting, the plants were uniformly thinned to 10 shoots per $\mathrm{m}^{-1}$. This planting density is common practice for the Kunming region. The soil chemical properties were $\mathrm{pH} 7.28$, total $\mathrm{N} 1.36 \mathrm{~g} \cdot \mathrm{kg}^{-1}$, total P $8.3 \mathrm{~g} \cdot \mathrm{kg}^{-1}$, total $\mathrm{K} 5.43 \mathrm{~g} \cdot \mathrm{kg}^{-1}$, available $\mathrm{N} 150$ $\mathrm{mg} \cdot \mathrm{kg}^{-1}$, available P $36.58 \mathrm{mg} \cdot \mathrm{kg}^{-1}$, available $\mathrm{K} 185.89$ $\mathrm{mg} \cdot \mathrm{kg}^{-1}$ and organic matter $45.6 \mathrm{~g} \cdot \mathrm{kg}^{-1}$.

\subsection{Supplemental UV-B Radiation}

Supplemental UV-B radiation was provided by filtered Gucun brand (Gucun Instrument Factory, Shanghai, China) $40 \mathrm{~W}$ sunlamps. The wavelength of sunlamps was $280-315 \mathrm{~nm}$ and maximum radiation was $310 \mathrm{~nm}$ (Li et al., 2008a). Lamps were suspended above and perpendicular to the planted rows (rows oriented in an east-west direction to minimize shading) and filtered with either $0.13 \mathrm{~mm}$ thick cellulose diacetate (transmission down to $290 \mathrm{~nm}$ ) for supplemental UV-B radiation or $0.13 \mathrm{~mm}$ polyester plastic films (absorbs all radiation $<320 \mathrm{~nm}$ ) as a control (Sullivan and Teramura, 1990). Cellulose diacetate filters were presolarized for 8 $\mathrm{h}$ and changed weekly to ensure uniformity of UV-B transmission. The spectral irradiance from the lamps was determined with an Optronics Model 742 (Optronics Laboratories Inc. Orlando, Florida, USA) spectroradiometer. The spectral irradiance was weighted with the generalized plant response action spectrum (Caldwell, 1971) and normalized at $300 \mathrm{~nm}$ to obtain UV-B ${ }_{B E}$. Six lamps were installed above each plot. The supplemental UV-B level was similar to that which would be experienced at Kunming $\left(25^{\circ} \mathrm{N}, 1950 \mathrm{~m}\right)$ with a $20 \%$ stratospheric ozone reduction during a clear day on the summer solstice $\left(10.00 \mathrm{~kJ} \mathrm{~m}^{-2} \mathrm{UV}-\mathrm{B}_{\mathrm{BE}}\right)$, according to a mathematical model of Madronich et al. (1995). Plants were irradiated for $7 \mathrm{~h}$ daily from April 30 (thinning) to August 15 (ripening stage) centered around solar noon. Plants under polyester-filtered lamps received only ambient levels of UV-B radiation $(10.00 \mathrm{~kJ}$ $\mathrm{m}^{-2} U \mathrm{UV}-\mathrm{B}_{\mathrm{BE}}$ during clear sky conditions on the summer solstice). Plants beneath the cellulose diacetate filters received ambient plus supplemental levels of UV-B. The lamp height above the plants was adjusted weekly to maintain a distance of $0.40 \mathrm{~m}$ between the lamps and the tops of plants and provided supplemental irradiances of 5.00 effective $\mathrm{kJ} \mathrm{m}^{-2} \mathrm{UV}-\mathrm{B}_{\mathrm{BE}}$. Total daily photosynthetic photon flux (PPF between 400-700 nm) under lamp fixtures was $90 \%$ of that above the lamps.

\subsection{Measurements}

Soil samples were collected at $0-30 \mathrm{~cm}$ depth at the ripening stage, air-dried and passed through a $2.0 \mathrm{~mm}$ sieve. Soil $\mathrm{pH}_{\mathrm{H} 2 \mathrm{O}}$ was measured in deionized water by potentiometry (soil-solution ratio 1:2.5). Soil Organic Carbon (SOC) was measured after $\mathrm{K}_{2} \mathrm{Cr}_{2} \mathrm{O}_{7}+\mathrm{H}_{2} \mathrm{SO}_{4}$ digestion and titration of excess oxidant with Mohr's salt. Available N was determined using a micro-diffusion technique after alkaline hydrolysis. Available $\mathrm{P}$ was determined by Olsen methods. Available K was extracted with $1 \mathrm{~N}$ ammonium acetate and analysed using an atomic absorption spectrophotometer. After mineralization with $\mathrm{Na}_{2} \mathrm{SO}_{4} \cdot \mathrm{Se}+\mathrm{H}_{2} \mathrm{SO}_{4}$, total $\mathrm{N}$ was measured using the Macro-Kjeldahl method. Total $\mathrm{P}$ was measured using $\mathrm{NaOH}+\left(\mathrm{NH}_{4}\right)_{2} \mathrm{MoO}_{4}$ spectrophotometry. Total $\mathrm{K}$ was measured using an atomic absorption spectrophotometer (TAS-990, Beijing General Instrument Co. Ltd., China) (Lao, 1988).

Plants in each plot were harvested at the ripening stage of wild sugarcane. Shoots were separated into stems and leaves. Samples of stems and leaves were oven-dried at $68^{\circ} \mathrm{C}$ for $68 \mathrm{~h}$, weighed and ground to pass through a 20 -mesh sieve and $\mathrm{N}$ content was determined by a semi-micro-Kjeldahl method (Bao, 2000). N mass of stems and leaves was calculated by multiplying $\mathrm{N}$ content by biomass per plot.

The contents of free amino acid, protein contents, nitrate reductase activities and glutamine synthetase activities were determined with the first 3 fully expanded fresh leaves from the top to the base of plants.

Fresh leaves were immediately frozen in liquid $\mathrm{N}$ and stored at $-80^{\circ} \mathrm{C}$ until processed. Frozen leaves (100-200 $\mathrm{mg}$ ) were ground in liquid $\mathrm{N}$ and extracted at $70^{\circ} \mathrm{C}$, twice with $500 \mathrm{~mL}$ EtOH $80 \%$ in Hepes $10 \mathrm{mM}$ pH 7.0 and once with $500 \mathrm{~mL}$ Hepes $10 \mathrm{mM} \mathrm{pH}$ 7.0. All supernatants were combined to give Extract I (containing free amino acids). The final pellet was resuspended in $0.5 \mathrm{~mL}$ Hepes 
$10 \mathrm{mM}$ pH 7.0 and $0.25 \mathrm{~mL}$ was recombined with half of Extract I. Total proteins in the recombined extract were hydrolyzed in the presence of $6 \mathrm{M}$ HClfree amino acids).

Free amino acids in Extract I and free amino acids + hydrolyzed proteins in Extract II were quantified using the ninhydrin method, according to Moore (1968). Ninhydrin reagent $(1 \mathrm{~mL})$ was mixed with $0.5 \mathrm{ml}$ of Extract I or $0.1 \mathrm{~mL}$ of Extract II and incubated for 20 min at $100^{\circ} \mathrm{C}$. After cooling and addition of EtOH $50 \%$, the solutions were vigorously mixed and absorbance recorded at $570 \mathrm{~nm}$ using a spectrophotometer (T6, PERSEE) (Moore, 1968; Tang, 1999).

Nitrate reductase activity in leaves is typically assayed in vivo by measuring $\mathrm{NO}_{2}^{-}$production in tissue that has been vacuum infiltrated with a buffered $\mathrm{NO}_{3}{ }^{-}$solution (Downs et al., 1993). The measurements of in vivo nitrate reductase activity were conducted using modification of the in vivo assay described by Jaworski (1971). The measurements were taken from samplings chosen on clear days between the hours of 1100 and 1300 local time. Immediately after collection, leaves were dissected into $2 \mathrm{~mm}$ segments and placed in test tubes with a buffer solution. Leaf tissue was then subjected to vacuum infiltration (with a manually operated vacuum pump) at $0.33 \mathrm{~atm}$ for $4 \mathrm{~h}$ at $20^{\circ} \mathrm{C}$ in the dark. The composition of the incubation buffer was $2 \mathrm{~mol} \cdot \mathrm{L}^{-1}$ $\mathrm{KNO}_{3}, 0.1 \mathrm{M} \mathrm{K}_{2} \mathrm{HPO}_{4}$, adjusted to $\mathrm{pH} 7.5$ with $\mathrm{HCl}$. After incubation, enzyme activity was terminated by the addition of $1 \%$ sulphanilamide in $8 \% \mathrm{HCl}$. The concentration of synthesized $\mathrm{NO}_{2}^{-}$in the incubation buffer was determined colorimetrically upon diazotization and the formation of azodye following the addition to the reaction mixture of $0.02 \% \mathrm{~N}$-(1-naphthyl) ethylenediamine-dihydrochloride (Keeney and Nelson, 1982). Optical density was measured colorimetrically after $10 \mathrm{~min}$ at $520 \mathrm{~nm}$ using a spectrophotometer (T6, PERSEE). Nitrate reductase activity was calculated on the basis of a calibration curve for $\mathrm{KNO}_{2}$. Results were expressed as the amount of $\mathrm{NO}_{2}{ }^{-}$synthesized in $\mu \mathrm{g}$ per leaves fresh weight per hour $\left(\mu \mathrm{g} \mathrm{NaNO}{ }_{3} \cdot \mathrm{g}^{-1} \cdot \mathrm{h}^{-1}\right)$.

The activity of glutamine synthetase in leaves was measured in a final volume of $5 \mathrm{ml}$ containing phosphate buffer ( $\mathrm{pH}$ 7.5) by the synthetase assay, as described by Tang (1999). The reaction was initiated by the addition of $50 \mu \mathrm{l}$ extract and was measured colorimetrically at $540 \mathrm{~nm}$ using a spectrophotometer (T6, PERSEE). Results were expressed as the amount of $\gamma$-glutamyl hydroxamate synthesized in $\mathrm{mg}$ per leaves fresh weight per hour $\left(\mathrm{A} \cdot \mathrm{mg}^{-1} \cdot \mathrm{h}^{-1}\right)$.

\subsection{Statistical Analysis}

Statistical differences between means of control and UV-B radiation treatment of measured parameters were analyzed by Student's t-test at $\mathrm{p}<0.05$. Correlation analyses were utilized to test correlation significance of $\%$ change between two measured parameters using SPSS 11.5 for Windows $(\mathrm{p}<0.05)$.

\section{RESULTS}

\subsection{Available N Content in Soil}

Available $\mathrm{N}$ contents in soil of four wild sugarcane clones were significantly decreased by $9.65-25.88 \%$ due to enhanced UV-B radiation (Table 2). No effect of enhanced UV-B radiation on available $\mathrm{N}$ contents in soil of two clones (92-11 and II91-5) was observed. The effect of UV-B radiation on available $\mathrm{N}$ contents in soil showed intraspecific differences. The highest change of available $\mathrm{N}$ contents in soil was $-25.50 \%$ of clone $90-15$ and $-25.88 \%$ of clones II91-72 and the lower one was 9.65 of clone 92-36.

\section{2. $\mathbf{N}$ Contents and $\mathbf{N}$ mass in Stems}

$\mathrm{N}$ contents in stems of six wild sugarcane clones were significantly decreased by -13.04 to $-21.74 \%$ due to enhanced UV-B radiation (Table 3). The effect of UV-B radiation on $\mathrm{N}$ content showed intraspecific differences. The highest change of $\mathrm{N}$ contents in stems was $-21.74 \%$ in clone 92-11 and the least was -13.04 in clone II 91-72.

Under UV-B radiation, the stem biomass of six wild sugarcane clones significantly increased by $39.00-131.91 \%$ (Table 3). The effect of UV-B radiation on stem biomass showed intraspecific differences. The highest change of stem biomass was $131.91 \%$ in clone $90-15$ and the least change was $39.00 \%$ in clones II $91-72$.

Stem N mass of six wild sugarcane clones were significantly increased by $20.82-93.86 \%$ by enhanced UV-B radiation (Table 3). The effects of UV-B radiation on stem $\mathrm{N}$ mass showed intraspecific differences. The highest change of stem $\mathrm{N}$ mass was $93.86 \%$ in clone 90 15 and the least was $20.82 \%$ in clones II90-5.

\section{3. $\mathbf{N}$ Contents and $\mathbf{N}$ Mass in Leaves}

$\mathrm{N}$ contents in the leaves of four wild sugarcane clones $(90-15,83-193,92-36$, II91-5) significantly decreased by -7.44 to $-14.05 \%$ due to enhanced UV-B radiation (Table 4). Whilst in the other two wild sugarcane clones, no changes in N contents due to UV-B radiation were observed. The effect of UV-B radiation on $\mathrm{N}$ content showed intraspecific differences. 
Yanqun Zu et al. / American Journal of Environmental Science 9 (6): 446-457, 2013

Table 2. Intraspecific responses in soil available $\mathrm{N}$ contents $\left(\mathrm{Mg} \mathrm{Kg}^{-1}\right)$ of 6 wild sugarcane (S. Spontaneum L.) clones to enhanced UV-B radiation at the ripening stage

\begin{tabular}{lllllll}
\hline Clones & $92-11$ & $90-15$ & $83-193$ & $92-36$ & II91-72 & II91-5 \\
\hline Control & $116.00 \pm 2.30$ & $123.38 \pm 3.31$ & $100.36 \pm 1.85$ & $116.30 \pm 2.13$ & $134.60 \pm 3.41$ & $113.64 \pm 3.22$ \\
UV-B & $116.30 \pm 3.10$ & $91.21 \pm 2.10$ & $89.14 \pm 1.56$ & $105.08 \pm 2.10$ & $99.77 \pm 2.11$ & $106.85 \pm 3.10$ \\
$\%$ change & 0.25 & $-25.50 * *$ & $-11.18^{*}$ & $-9.65 *$ & $-25.88^{* *}$ & -5.98 \\
\hline
\end{tabular}

Results are mean \pm SD of 3 replications. LSD test: $*$ and ${ }^{* *}$ denotes significance at $\mathrm{p}<0.05$ and $\mathrm{p}<0.01$ by $\mathrm{t}$-tests, respectively

Table 3. Intraspecific responses in N contents, biomass and $\mathrm{N}$ mass in stems of 6 wild sugarcane $(S$. spontaneum) clones to enhanced UV-B radiation at the ripening stage

\begin{tabular}{|c|c|c|c|c|c|c|c|c|c|}
\hline \multirow[b]{2}{*}{ Clones } & \multicolumn{3}{|c|}{$\mathrm{N}$ contents $(\%)$} & \multicolumn{3}{|c|}{ Biomass $\left(\mathrm{kg} \cdot \mathrm{m}^{-2}\right)$} & \multicolumn{3}{|c|}{$\mathrm{N}$ mass $\left(\mathrm{g} \cdot \mathrm{m}^{-2}\right)$} \\
\hline & Control & $+U V-B$ & $\%$ change & Control & $+U V-B$ & $\%$ change & Control & +UV-B & $\%$ change \\
\hline $92-11$ & $0.69 \pm 0.03$ & $0.54 \pm 0.02$ & $-21.74 * *$ & $0.89 \pm 0.03$ & $1.89 \pm 0.05$ & $112.36^{* *}$ & $6.14 \pm 0.08$ & $10.21 \pm 0.06$ & $66.29 * *$ \\
\hline $90-15$ & $0.87 \pm 0.02$ & $0.69 \pm 0.02$ & $-20.69 * *$ & $1.41 \pm 0.06$ & $3.27 \pm 0.09$ & $131.91 * *$ & $12.27 \pm 0.07$ & $22.56 \pm 0.12$ & $93.86 * *$ \\
\hline $83-193$ & $0.89 \pm 0.03$ & $0.71 \pm 0.02$ & $-20.22 * *$ & $0.46 \pm 0.02$ & $0.93 \pm 0.03$ & $102.18 * *$ & $4.09 \pm 0.04$ & $6.60 \pm 0.07$ & $61.37 * *$ \\
\hline $92-36$ & $0.87 \pm 0.03$ & $0.71 \pm 0.02$ & $-18.40 *$ & $0.51 \pm 0.02$ & $1.13 \pm 0.04$ & $121.56^{* *}$ & $4.44 \pm 0.09$ & $8.02 \pm 0.08$ & $80.64 * *$ \\
\hline II91-72 & $0.92 \pm 0.03$ & $0.80 \pm 0.03$ & $-13.04 * *$ & $1.02 \pm 0.05$ & $1.42 \pm 0.04$ & $39.00 * *$ & $9.38 \pm 0.06$ & $11.36 \pm 0.09$ & $21.11 *$ \\
\hline II91-5 & $1.03 \pm 0.04$ & $0.87 \pm 0.03$ & $-15.53 *$ & $0.56 \pm 0.02$ & $0.94 \pm 0.03$ & $67.86^{* *}$ & $5.60 \pm 0.05$ & $17.26 \pm 0.07$ & $20.82 *$ \\
\hline
\end{tabular}

Results are mean \pm SD of 3 replications. *and**denotes significance at $\mathrm{p}<0.05$ and $\mathrm{p}<0.01$ by $\mathrm{t}$-tests, respectively

Table 4. Intraspecific Responses in N Contents, Biomass and N Mass in Leaves of 6 Wild Sugarcane (S. Spontaneum) Clones to Enhanced UV-B Radiation at The Ripening Stage

\begin{tabular}{|c|c|c|c|c|c|c|c|c|c|}
\hline \multirow[b]{2}{*}{ Clones } & \multicolumn{3}{|c|}{$\mathrm{N}$ contents $(\%)$} & \multicolumn{3}{|c|}{ Biomass $\left(\mathrm{kg} \cdot \mathrm{m}^{-2}\right)$} & \multicolumn{3}{|c|}{$\mathrm{N}$ mass $\left(\mathrm{g} \cdot \mathrm{m}^{-2}\right)$} \\
\hline & Control & +UV-B & $\%$ change & Control & +UV-B & $\%$ change & Control & +UV-B & $\%$ change \\
\hline $92-11$ & $1.39 \pm 0.11$ & $1.36 \pm 0.10$ & -2.16 & $1.20 \pm 0.05$ & $2.81 \pm 0.12$ & $92.50 *$ & $16.69 \pm 0.06$ & $38.22 \pm 0.12$ & $129.00 * *$ \\
\hline $90-15$ & $1.21 \pm 0.08$ & $1.04 \pm 0.06$ & $-14.05 * *$ & $1.35 \pm 0.13$ & $3.38 \pm 0.15$ & $150.37 * *$ & $16.34 \pm 0.10$ & $35.15 \pm 0.09$ & $115.12 * *$ \\
\hline $83-193$ & $1.21 \pm 0.06$ & $1.12 \pm 0.09$ & $-7.44 *$ & $0.25 \pm 0.02$ & $0.66 \pm 0.05$ & $164.00 * *$ & $3.03 \pm 0.01$ & $7.39 \pm 0.05$ & $123.93 * *$ \\
\hline $92-36$ & $1.70 \pm 0.12$ & $1.56 \pm 0.11$ & $-8.24 *$ & $0.31 \pm 0.02$ & $0.66 \pm 0.08$ & $112.90 * *$ & $5.27 \pm 0.02$ & $13.42 \pm 0.09$ & $102.96 * *$ \\
\hline II91-72 & $1.21 \pm 0.08$ & $1.16 \pm 0.06$ & -4.13 & $0.81 \pm 0.09$ & $1.18 \pm 0.08$ & $45.68 *$ & $9.80 \pm 0.07$ & $13.69 \pm 0.08$ & $39.69^{*}$ \\
\hline II91-5 & $1.64 \pm 0.10$ & $1.50 \pm 0.07$ & $-8.54 *$ & $0.33 \pm 0.02$ & $0.71 \pm 0.07$ & $115.15^{* *}$ & $5.41 \pm 0.02$ & $10.65 \pm 0.06$ & $98.86 * *$ \\
\hline
\end{tabular}

Results are mean \pm SD of 3 replications. *and**denotes significance at $\mathrm{p}<0.05$ and $\mathrm{p}<0.01$ by $\mathrm{t}$-tests, respectively

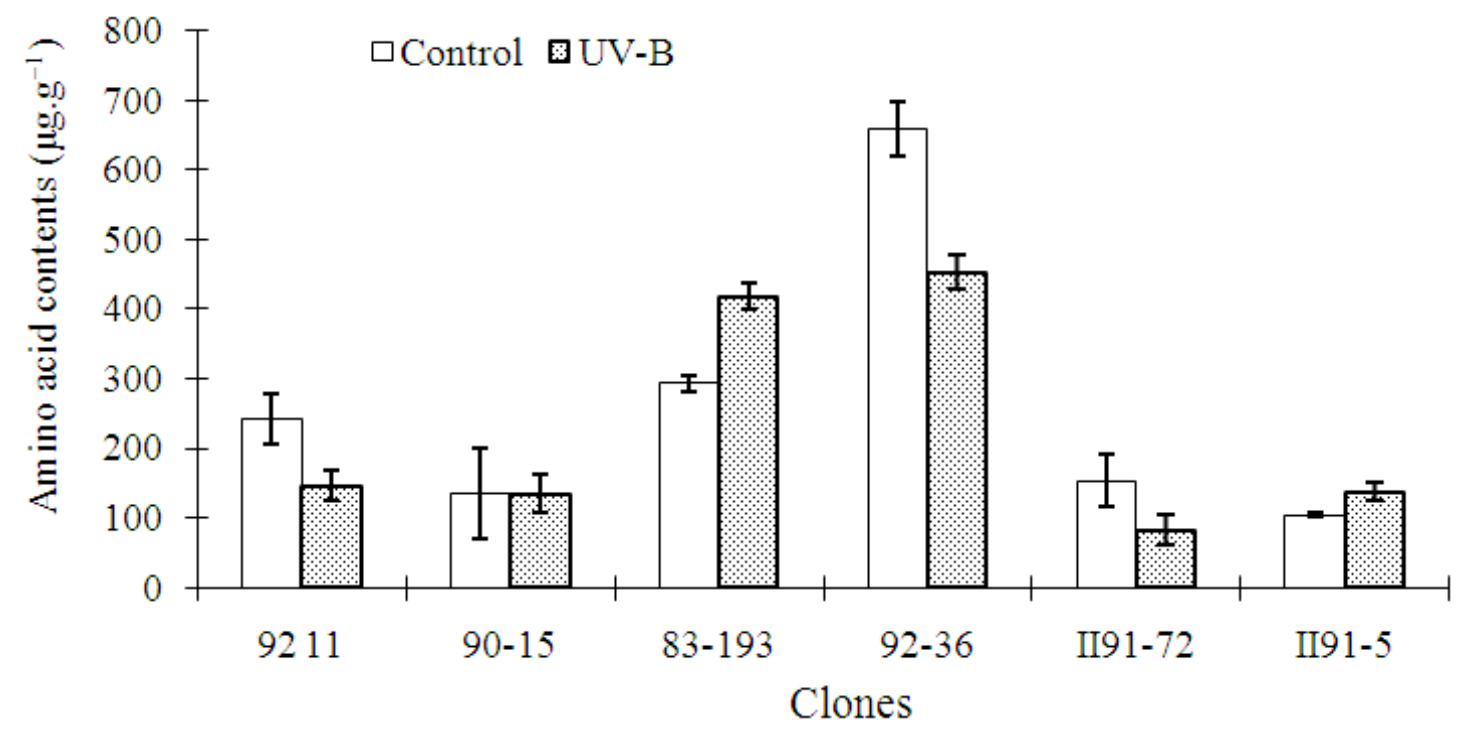

Fig. 1. Intraspecific responses in free amino acid contents in leaves of 6 wild sugarcane (S. spontaneum) clones to enhanced UV-B radiation at ripening stage. (Results are mean $\pm \mathrm{SD}$ of 3 replications. $*$ denotes significance at $\mathrm{p}<0.05$ by t-tests) 


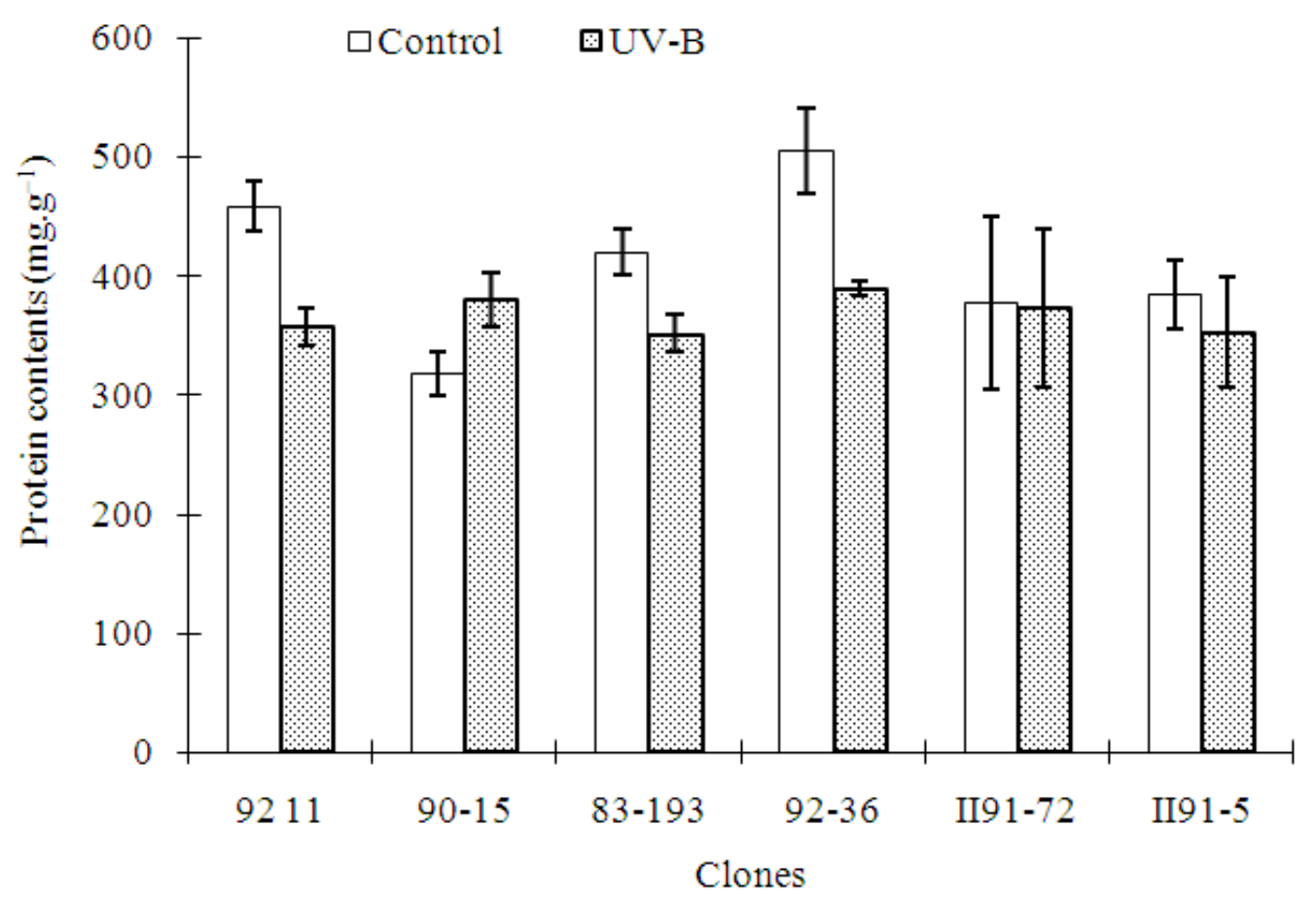

Fig. 2. Intraspecific responses in total protein contents in leaves of 6 wild sugarcane (S. spontaneum) clones to enhanced UV-B radiation at ripening stage. (Results are mean $\pm \mathrm{SD}$ of 3 replications. *denotes significance at $\mathrm{P}<0.05$ by t-test)

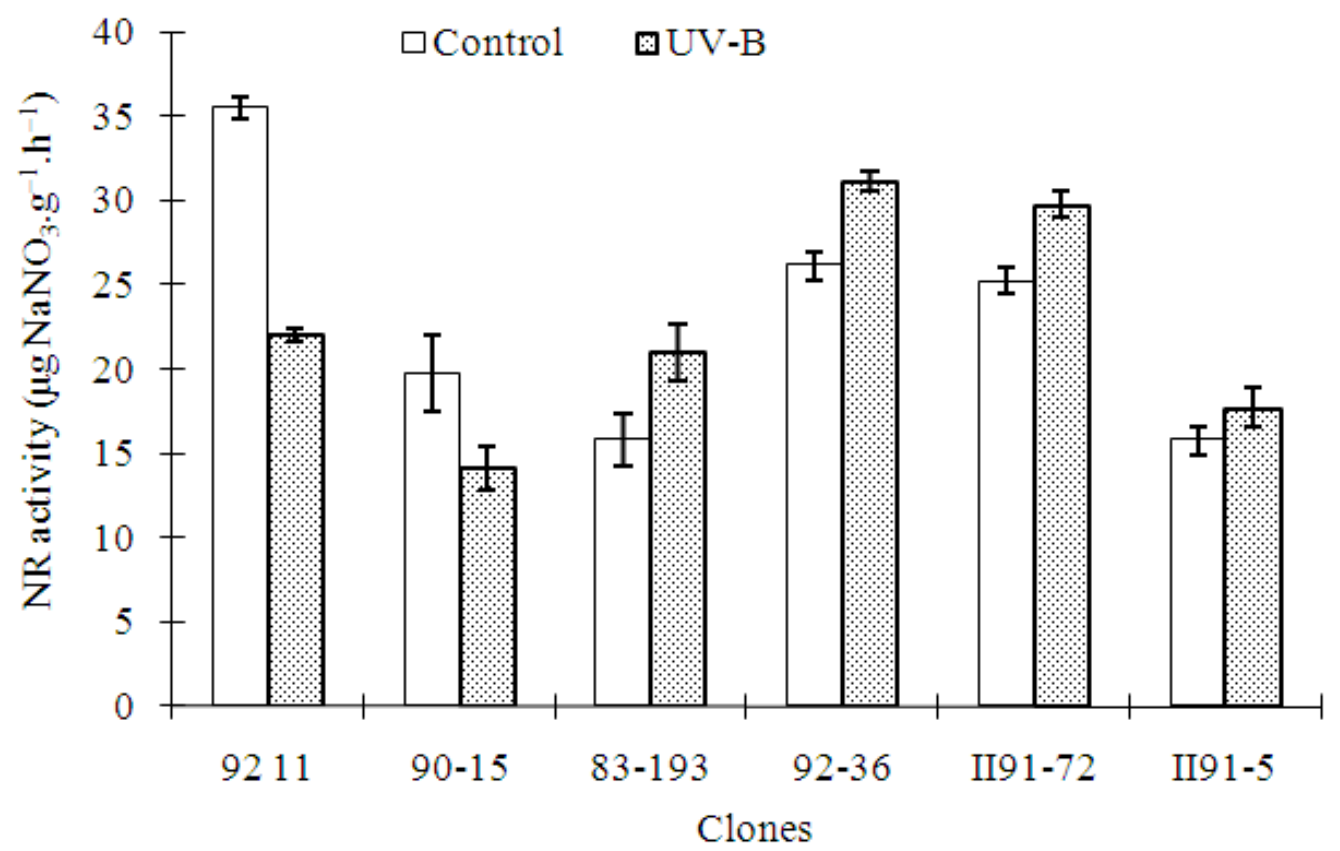

Fig. 3. Intraspecific responses in NR activity in leaves of 6 wild sugarcane (S. spontaneum) clones to enhanced UV-B radiation at ripening stage. (Results are mean $\pm \mathrm{SD}$ of 3 replications. *denotes significance at $\mathrm{p}<0.05$ by t-test) 


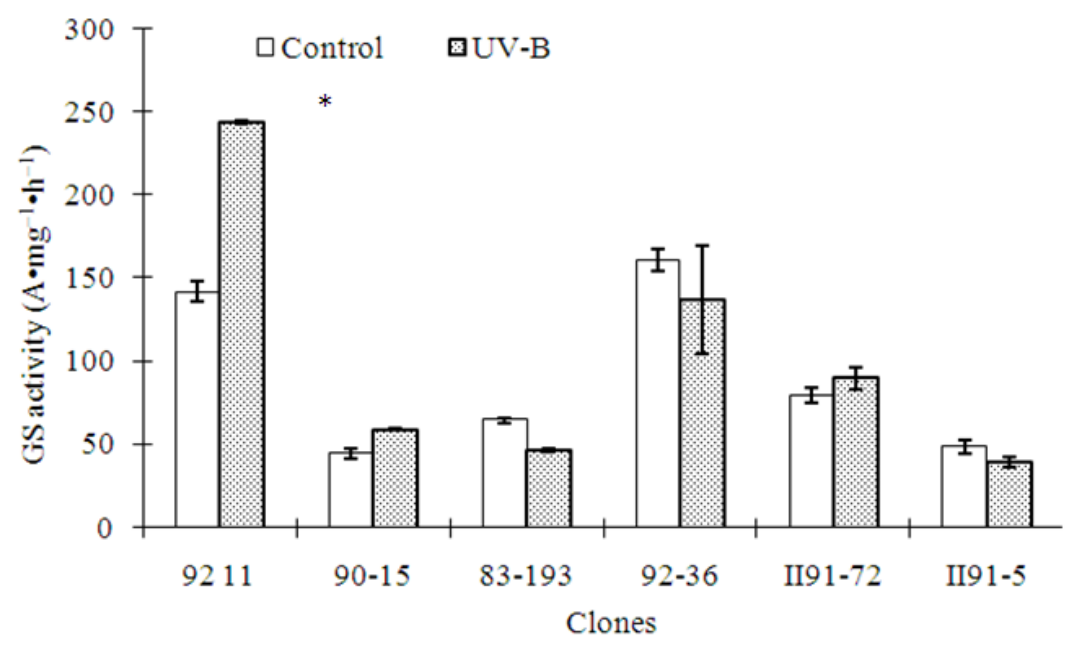

Fig. 4. Intraspecific responses in GS activity in leaves of 6 wild sugarcane (S. spontaneum) clones to enhanced UV-B radiation at ripening stage. (Results are mean $\pm \mathrm{SD}$ of 3 replications. *denotes significance at $\mathrm{P}<0.05$ by t-test)

The highest change of $\mathrm{N}$ contents was $-14.05 \%$ in clone 90-15 and the least was -7.44 in clone 83-193.

Under UV-B radiation, leaf biomass of six wild sugarcane clones significantly increased by 45.68 $164.00 \%$ (Table 4). The effect of UV-B radiation on biomass of leaves showed intraspecific differences. The highest change of biomass of leaves was $164.00 \%$ in clone 83-193 and the least was $45.68 \%$ in clone II91-72.

Leaf $\mathrm{N}$ mass of six wild sugarcane clones significantly increased by $39.69-129.00 \%$ due to enhanced UV-B radiation (Table 4). The effect of UV-B radiation on leaf $\mathrm{N}$ mass showed intraspecific differences. The highest change of leaf $\mathrm{N}$ mass was $129.00 \%$ in clone $92-11$ and the least was $39.69 \%$ in clone II $91-72$.

\subsection{The Contents of Free Amino Acid and Total Protein in Leaves}

Contents of free amino acid of two wild sugarcane clones (92-11 and 92-36) significantly decreased by 39.01 and $31.09 \%$, respectively, whilst that of clones $83-$ 193 and II91-5 significantly increased by 42.46 and $32.47 \%$, respectively, under enhanced UV-B radiation (Fig. 1). The effect of UV-B radiation on contents of free amino acid showed intraspecific differences.

Under UV-B radiation, total protein contents of three wild sugarcane clones 92-11, 83-193 and 92-36 significantly decreased by $22.08,16.26$ and $22.97 \%$, respectively, whilst that of clone 90-15 significantly increased by $19.17 \%$ (Fig. 2). No effect of enhanced UV-B radiation on total protein contents of clones II9172 and II91-5 was observed. The effect of UV-B radiation on total protein contents showed intraspecific differences.

\subsection{The Activity of Nitrate Reductase and Glutamine Synthetase in Leaves}

The activities of nitrate reductase (NR) of two wild sugarcane clones (92-11 and 90-15) significantly decreased by 38.01 and $28.31 \%$, respectively, whilst that of the other four clones significantly increased by 12.36 32.91\% under enhanced UV-B radiation (Fig. 3).

Under UV-B radiation, the activities of glutamine synthetase (GS) of two wild sugarcane clones (92-11 and 90-15) significantly increased by 71.81 and $31.57 \%$, respectively, whilst that of clone 83-193 significantly decreased by $28.10 \%$ (Fig. 4). No effects of enhanced UV-B radiation on the activities of glutamine synthetase of three wild sugarcane clones (92-36, II91-72 and II905) were observed.

\section{DISCUSSION}

To our knowledge, this is the first report to suggest the existence of intraspecific responses in $\mathrm{N}$ mass and $\mathrm{N}$ metabolism of six wild sugarcane ( $S$. spontaneum) clones differing in UV sensitivity to enhanced UV-B radiation under field conditions.

\subsection{UV-B Radiation and N Mass}

$\mathrm{N}$ contents in stems and leaves of six wild sugarcane clones decreased under UV-B radiation. Decreased N 
content in above-ground organs of Pisum sativum, soybean, rice, peas and maize was verified due to the reduction of $\mathrm{N}$ uptake, decreased transpiration rate, inhibition of the activity of key enzymes of $\mathrm{N}$ metabolism and the inhibition of ATP synthesis under UV-B stress (Peng and Zhou, 2010; Correia et al., 2012). The decrease of $\mathrm{N}$ contents in soils under enhanced UV$\mathrm{B}$ radiation implicated complexities of $\mathrm{N}$ uptake and $\mathrm{N}$ cycling within the plant-soil system. Increases of $\mathrm{N}$ contents in some plant organs and/or plant species were reported (Chen and Zhang, 2006; Reifenrath and Muller, 2007). The different results indicate that the responses of plant $\mathrm{N}$ content to UV-B radiation are complex and may be related to $\mathrm{N}$ metabolic processes, plant growth stages, species, biomass and concentration effects.

Biomass of stems and leaves six wild sugarcane clones increased under UV-B radiation. Some studies showed that UV-B radiation decreased the dry weight of leaves and inhibited growth (Kumari et al., 2009; Sangtarash et al., 2009; Peng and Zhou, 2010). The different phenomena might be related to the photosynthetic pigment contents and because the height of some wild sugarcane clones increased under UV-B radiation ( $\mathrm{Li}$ et al., 2008a). More UV-B-absorbing compounds and the photosynthetic performance of some wild sugarcane clones with high altitude origin as $\mathrm{C}_{4}$ plants might be enhanced at ambient UV-B levels. A significant positive correlation between altitude and biomass of leaves was observed $(r=0.847, n=6$, $\mathrm{p}<0.05$ ). Paponov and Engels (2003) also reported that two maize genotypes kept higher photosynthesis rates under environmental stress conditions. Because the biomass of six wild sugarcane clones included just above-ground biomass, the below-ground biomass might also respond to UV-B treatment, which merits research.

UV-B radiation decreased $\mathrm{N}$ contents in stems and leaves and increased the accumulation of dry matter, leading to increased $\mathrm{N}$ mass in stems and leaves. A significant negative correlation between $\%$ changes of $\mathrm{N}$ contents in stem and stem biomass was observed $(\mathrm{r}=$ $0.798, \mathrm{n}=6, \mathrm{p}<0.05$ ). Some previous findings showed that leaf $\mathrm{N}$ mass of spring wheat increased at ripening stage due to enhanced UV-B radiation. Significant positive correlations between $\%$ changes of stem biomass and stem $\mathrm{N}$ mass $(\mathrm{r}=0.957, \mathrm{n}=6, \mathrm{p}<0.01)$ and leaves $\mathrm{N}$ mass $(\mathrm{r}=0.822, \mathrm{n}=6, \mathrm{p}<0.05)$ were observed. The effect of biomass in organs on $\mathrm{N}$ mass should be more important than $\mathrm{N}$ content in organs. A significant positive correlation between leaves $\mathrm{N}$ mass and $\mathrm{RI}(\mathrm{r}=$ $0.838, \mathrm{n}=6, \mathrm{p}<0.05$ ) was observed, which suggests that the responses of leaf $\mathrm{N}$ mass and RI to UV-B radiation are consistent. This is a possible mechanism explaining the effect of UV-B radiation on $\mathrm{N}$ accumulation in wild sugarcane. UV-B radiation may lead to $\mathrm{N}$ cycling more rapidly and thus decreased soil $\mathrm{N}$ pool storage in areas where the above-ground parts of wild sugarcane are harvested.

\subsection{UV-B Radiation and N Metabolisms}

$\mathrm{N}$ accumulation of wild sugarcane was related to contents of $\mathrm{N}$ compounds, such as amino acid and protein. No significant correlation between $\mathrm{N}$ mass and contents of amino acid and protein was observed, except for stem $\mathrm{N}$ mass and protein content in leaves $(\mathrm{r}=0.852$, $\mathrm{n}=6, \mathrm{p}<0.05)$. This suggests that $\mathrm{N}$ accumulation of wild sugarcane should not only be influenced by $\mathrm{N}$ compounds, but also $\mathrm{N}$ metabolism processes.

Enhanced UV-B radiation led to decreased activities of nitrate reductase in leaves of two tolerant wild sugarcane clones. Enhanced UV-B radiation inhibited growth and decreased nitrate reductase activity in dragon spruce (Picea asperata Mast.) needles (Yao and Liu, 2007) and in young crop seedlings (Ghisi et al., 2002; Niu et al., 2007; Yao and Liu, 2007). A decrease in photosynthesis or $\mathrm{NO}_{3}^{-}$content has been observed in some cases (Rajendiran and Ramanujam, 2006; Yao and Liu, 2007). A significant negative correlation between leaves $\mathrm{N}$ mass and \% changes of $\mathrm{NR}(\mathrm{r}=-0.984, \mathrm{n}=6$, $\mathrm{p}<0.01)$ was observed. The activities of nitrate reductase depend on stomatal conductance, photosynthetic pigments (Barufi et al., 2011) and inhibition of stomatal opening due to UV-A radiation (Chen and Zhang, 2006). This could explain the activities of nitrate reductase being inhibited in tolerant wild sugarcane clones. UV-B radiation, similar to other stresses, induces the synthesis of a new set of proteins in both chloroplasts and cytoplasm, which may protect against structural and functional damage. Environmental stress may increase the resistance of plants by increasing their production of phenolics, stress proteins and enzyme proteins involved in antioxidant scavenging metabolisms ( $\mathrm{Xu}$ and Zhou, 2007; Krywult et al., 2008).

The increases in activities of glutamine synthetase of two tolerant clones could assist free amino acid transfer to amide or protein. A significant positive correlation between leaf $\mathrm{N}$ mass and \% changes of GS activities ( $\mathrm{r}=$ $0.928, \mathrm{n}=6, \mathrm{p}<0.01$ ) was observed. A similar conclusion was drawn by Dai et al. (1994) and Niu et al. (2007). The increase in activities of glutamine synthetase could improve $\mathrm{N}$ metabolism and amino acid assimilation. A significant positive correlation between protein content and GS activities $(\mathrm{r}=0.894, \mathrm{n}=6, \mathrm{p}<0.05)$ was observed under non-enhanced UV-B radiation. This correlation did 
not exist under enhanced UV-B radiation, which indicates that protein contents should not only depend on GS activity but also plant tolerance to enhanced UV-B radiation. The contents of free amino acid decreased, which would increase plant tolerance of enhanced UV-B radiation. Results suggested the mechanism of two tolerant clones could be different. The present study could rule out the possibility that some tolerant wild sugarcane clones might exhibit more efficient $\mathrm{N}$ assimilation in response to the effects of global stratospheric ozone depletion.

The decreases in the contents of free amino acid and total protein of tolerant wild sugarcane clones may be relative to decreases in nitrate reductase activity and increases in glutamine synthetase activity. A significant negative correlation between \% changes of nitrate reductase activity and glutamine synthetase activity was observed $(\mathrm{r}=-0.914, \mathrm{n}=6, \mathrm{p}<0.01)$.

The activities of nitrate reductase of middle and sensitive clones significantly increased under enhanced UV-B radiation. A similar conclusion was made by Niu et al. (2007) after analysis of photosynthetic pigments in wheat. Increases in the activities of nitrate reductase due to UV-B radiation is probably related to increased rates of photosynthesis, the enzymatic processes of $\mathrm{N}$ assimilation and biochemical processes in middle and sensitive wild sugarcane clones (Krywult et al., 2008). However, the activities of glutamine synthetase of middle and sensitive clones decreased or remained stable under enhanced UV-B radiation, which should result in free amino acid accumulation. UV stress is known to generate reactive oxygen, which results in a higher demand for the enzyme proteins involved in antioxidant scavenging metabolisms (Turunen and Latola, 2005; Krywult et al., 2008). Increases in the contents of free amino acid of middle and sensitive wild sugarcane clones were relative to increases in the activities of nitrate reductase and decreases in the activities of glutamine synthetase with general decreases in total protein contents. The higher contents of amino acid reflected a lower demand for stress proteins and/or higher demand for enzyme proteins. Free amino acid comes from assimilation of $\mathrm{N}$ and decomposition of structural protein, which suggested structure and function were damaged under enhanced UV-B radiation.

\subsection{Intraspecific Differences to UV-B}

Intraspecific responses in $\mathrm{N}$ mass and $\mathrm{N}$ metabolism of wild sugarcane ( $S$. spontaneum) clones differing in UV sensitivity to enhanced UV-B radiation under field conditions were complex, as observed in the six wild sugarcane clones used in this experiment. Complex responses were also evident in plant growth, plant height, morphology ( $\mathrm{Zu}$ et al., 2007; Li et al., 2008b), physiology (Li et al., 2008b), flavonoid content (Li et al., 2006b), cell membrane permeability (Li et al., 2006a), brix (Li et al., 2007) and rhizosphere microbial community including microbial species, population dynamics and diversity ( $\mathrm{Zu}$ et al., 2005) of wild sugarcane clones. However, out of these clones, the ranking of every indicator was different.

The Response Index (RI) is an integration of the effect of UV-B radiation on plant height, LAI, tiller number, shoot biomass and brix of 23 wild sugarcane clones in the previous experiment, which could reflect the overall sensitivity of wild sugarcane clones to enhanced UV-B radiation ( $\mathrm{Li}$ et al., 2008a). In the six wild sugarcane clones, correlation analysis showed that RI significantly correlated with $\%$ changes of $\mathrm{N}$ contents in stem $(\mathrm{r}=-0.912, \mathrm{n}=6, \mathrm{p}<0.05)$, nitrate reductase activity $(\mathrm{r}=-0.816, \mathrm{n}=6, \mathrm{p}<0.05)$ and glutamine synthetase activity $(\mathrm{r}=0.802, \mathrm{n}=6, \mathrm{p}<0.05)$, respectively. UV-B radiation significantly affected $\mathrm{N}$ contents, nitrate reductase activity and glutamine synthetase activity of wild sugarcane clones, thus resulting in differences in RI.

There was no significant correlation between RI and $\%$ changes of biomass. UV-B radiation had significant effects on leaf $\mathrm{N}$ mass of six wild sugarcane clones. This showed that the effect of UV-B radiation on $\mathrm{N}$ content was related to UV-B sensitivity of wild sugarcane clones. Tevini et al. (1990) demonstrated that in rye the dosedependent increases in flavonoid production is sufficient to fully protect the physiological machinery from UVinduced damage. Intraspecific variations in UV-B sensitivity in wild sugarcane clones may also be related to differences in the concentration of UV-B absorbing compounds in leaves (Li et al., 2006b). In spinach and beans, however, this relationship was not found. It is suggested that intraspecific differences in UV-B sensitivity may arise through a complex of specific responses, rather than a generalized response.

Intraspecific responses to supplemental UV-B radiation had been demonstrated in some species, including wheat (Li et al., 2006a), soybean (Xu et al., 2008), Hippophae rhamnoides (Yang et al., 2008), E. breviscapus (Feng et al., 2009) and rice (Fedina et al., 2010). Populations originating from naturally high UV-B radiation locations have been shown to be less sensitive to UV-B radiation than those from low intensity UV-B radiation locations (Roblek et al., 2008). UV-B sensitivity of different plant populations significantly decreased with 
increasing altitude of original habitat (Sullivan, 2005). Clones 92-11, 90-15 and 83-193 originated from higher altitudes or lower latitudes (Li et al., 2008a). Because of long-term living under higher UV-B radiation intensity, these three clones may form adaptive mechanisms to enhanced UV-B radiation, by having higher antioxidant capacity and accumulative capacity of flavonoid (Li et al., 2006b). However, clones 92-36, II91-72 and II91-5 from lower altitudes are more sensitive to enhanced UV-B radiation than those from higher altitudes (Li et al., 2008a).

Intraspecific responses in $\mathrm{N}$ mass and $\mathrm{N}$ metabolism of wild sugarcane ( $S$. spontaneum) clones differing in UV sensitivity to enhanced UV-B radiation under field conditions depends on both the environment and genetic diversity among populations. According to RAPD assay, these six wild sugarcane (S. spontaneum) clones were divided into tolerant group and sensitive group at the genetic distance of 0.380 (Li et al., 2011). The two DNA clones were determined to be linked to the UV-B tolerant and sensitive genes and they can be used to develop molecular markers for associated traits (Li et al., 2011). This classification was consistent with the RI results (Li et al., 2008a). Because of geographic isolation and environmental differences, differentiations of genetics and ecological habits occurred among wild sugarcane clones from different original habitats. The different results should be relative to genetypes, clones, species, original altitude and latitude, naturally high UV-B environment, intensity of UV-B radiation and photosynthetic processes (Sullivan, 2005; Li et al., 2006a).

\section{CONCLUSION}

$\mathrm{N}$ mass and $\mathrm{N}$ metabolism can be used as indicators of the sensitivity of wild sugarcane clones to enhanced UV-B radiation under field conditions. In six wild sugarcane clones, the responses of each $\mathrm{N}$ mass and $\mathrm{N}$ metabolism characteristics to UV-B radiation were different. Little is known about the response mechanisms of wild sugarcane clones to UV$\mathrm{B}$ radiation. To better understand these mechanisms, it is necessary to study a broad range of plant nutrients and physiological and genetic responses to UV-B radiation under field conditions.

\section{ACKNOWLEDGEMENT}

This work was supported by the National Natural Science Foundation of China (No. 30260036, 31060083 and 41205113). We wish to thank the Sugarcane
Research Institute, Yunnan Agricultural University, for supporting the experimental work and Professor Michael A. Fullen for his valuable comments and English editing.

\section{REFERENCES}

Albert, K.R., T.N. Mikkelsen and H. Ro-Poulsen, 2008. Ambient UV-B radiation decreases photosynthesis in high arctic Vaccinium uliginosum. Physiol. Plant., 133: 199-210. DOI: 10.1111/j.13993054.2008.01065.x

Bao, S.D., 2000. Soil Agro-Chemical Analysis. 1st Edn., Chinese Agricultural Press, Beijing.

Barufi, J.B., N. Korbee, M.C. Oliveira and F.L. Figueroa, 2011. Effects of $\mathrm{N}$ supply on the accumulation of photosynthetic pigments and photoprotectors in Gracilaria tenuistipitata (Phodophyta) cultured under UV radiation. J. Applied Phycol., 23: 457-466. DOI: 10.1007/s10811-010-9603-X

Beckmann, M., M. Hock, H. Bruelheide and A. Erfmeier, 2012. The role of UV-B radiation in the invasion of Hieracium pilosella? A comparison of German and New Zealand plants. Environ. Exp. Bot., 75: 173-180. DOI: 10.1016/j.envexpbot.2011.09.010

Caldwell, M.M., 1971. Solar UV-B Irradiation and the Growth and Development of Higher Plant. In: Photophysiology, Giese, A.C. (Ed.), Academic Press, New York, pp: 131-1 71.

Canovas, F.M., C. Avila, F.R. Canton, R.A. Canasa and F. de la Torre, 2007. Ammonium assimilation and amino acid metabolism in conifers. J. Exp. Bot., 58: 2307-2318. DOI: 10.1093/jxb/erm051

Chen, L. and S.R. Zhang, 2006. Effects of enhanced UV$B$ radiation on water use efficiency, stomatal conductance, leaf nitrogen content and morphological characteristics of Spiraea pubescens in a warm-temperate deciduous broad forest. J. Plant Ecol., 30: 47-56.

Correia, C.M., J.F. Coutinho, E.A. Bacelar, B.M. Goncalves and L.O. Bjorn et al., 2012. Ultraviolet-B radiation and nitrogen affect nutrient concentrations and the amount of nutrients acquired by aboveground organs of maize. Sci. World J. DOI: $10.1100 / 2012 / 608954$

Correia, C.M., J.M.M. Pereira, J.F. Coutinho, L.O. Björn and M.G. Torres-Pereira, 2005. Ultraviolet-B radiation and nitrogen affect the photosynthesis of maize: A Mediterranean field study. Eur. J. Agro., 22: 337-347. DOI: 10.1016/j.eja.2004.05.002 
Dai, Q.J., S.B. Peng and V.P. Coronel, 1994. Intraspecific responses of 188 rice cultivars to enhanced UV-B radiation. Environ. Exp. Bot., 34: 433-442. DOI: 10.1016/0098-8472(94)90026-4.

Downs, M.R., K.J. Nadelhoffer, J.M. Melillo and J.D. Aber, 1993. Foliar and fine root nitrate reductase activity in seedlings of four forest tree species in relation to nitrogen availability. Trees, 7: 233-236. DOI: 10.1007/BF00202079

Fedina, I., J. Hidema, M. Velitchkova, K. Ggorgieva and D. Nedeva, 2010. UV-B induced stress responses in three rice cultivars. Biol. Plant, 54: 571-574. DOI: 10.1007/s10535-010-0102-3.

Feng, Y., Y. Zhu, Y.Q. Zu, S.C. Yang and J.J. Chen et al., 2009. Physiological differences and their genetic backgrounds of Erigeron breviscapus populations under enhanced UV-B radiation. Ying Yong Sheng Tai Xue Bao., 20: 2935-2942. PMID: 20353059

Ghisi, R., A.R. Trentin, A. Masi and M. Ferretti, 2002. Carbon and nitrogen metabolism in barley plants exposed to UV-B radiation. Physiol. Plant., 116: 200-205. DOI: $\quad 10.1034 /$ j.13993054.2002.1160209.x

Jaworski, E.G., 1971. Nitrate reductase assay in intact plant tissue. Biochem. Biophy. Res. Commun., 43: 1274-1279. DOI: 10.1016/S0006-291X(71)80010-4.

Kakani, V.G., G.K. Surabhi and K.R. Reddy, 2008. Photosynthesis and fluorescence responses of $\mathrm{C} 4$ plant Andropogon gerardii acclimated to temperature and carbon dioxide. Photosynthetica, 46: 420-430. DOI: 10.1007/s11099-008-0074-0

Keeney, D.R. and D.W. Nelson, 1982. NitrogenInorganic Forms. In: Methods of Soil Analysis, Part 2. Agronomy 9, Page, A.L. (Ed.), American Society of Agronomy, Inc., Soil Science Society of America, Inc., Madison, WI, USA., pp: 643-698.

Krywult, M., J. Smykla, H. Kinnunen, F. Martz and M.L. Sutinen et al., 2008. Influence of solar UV radiation on the nitrogen metabolism in needles of Scots pine (Pinus sylvestris L.). Environ. Pollut., 156: 11051111. DOI: 10.1016/j.envpol.2008.04.009

Kumari, R., S. Singh and S.B. Agrawal, 2009. Combined effects of Psoralens and ultraviolet-B on growth, pigmentation and biochemical parameters of Abelmoschus esculentus L. Ecotoxi. Environ. Safe, 72: 1129-1136. DOI: 10.1016/j.ecoenv.2008.12.009

Lao, J.C., 1988. Booklet of Soil Agro-chemical Analysis. 1st Edn., Agricultural Press, Beijing, China.
Li, Y., Y.M. He, L. Qin and Y.Q. Zu, 2008b. Intraspecific diferences in morphology and physiology of two wild sugarcane clones to enhanced UV-B radiation under field conditions. J. Agro-Environ. Sci., 27: 1956-1962.

Li, Y., Y.M. He, Y.Q. Zu and F.D. Zhan, 2011. Identification and cloning of molecular makers for UV-B tolerant gene in wild sugarcane (Saccharum spontaneum L.). J. Photochem. Photobiol. B: Biol., 105: 119-125. DOI: 10.1016/j.jphotobiol.2011.07.002

Li, Y., Y.Q. Zu, L. Qin, Y.M. He, C.P. Zhang and L.L. He, 2007. Effects of three years' enhanced UV-B radiation on birxs of 33 wild sugarcane (Saccharum spontaneum L.) clones at ripening stage. J. AgroEnviron. Sci., 26: 1014-1018.

Li, Y., Y.Q. Zu, Y.M. He and J.J. Chen, 2006b. Intraspecific responses in flavonoid contents of 28 wild sugarcane clones to enhanced ultraviolet-B radiation under field conditions. Am. J. Plant Physiol., 1: 151-159. DOI: 10.3923/ajpp.2006.151.159

Li, Y., Y.Q. Zu, Y.M. He, H.Y. Chen and J.J. Chen et al., 2006a. Responses in ion leakage of wild sugarcane (Saccharum spontaneum L.) clones to enhanced ultraviolet-B radiation under field conditions. Acta Physiol. Plant, 28: 401-408. DOI: 10.1007/BF02706622

Li, Y., Y.Q. Zu, Y.M. He, H.Y. Chen and J.J. Chen et al., 2008a. Variations in growth responses of 23 wild sugarcane (Saccharum spontaneum L.) clones to enhanced ultraviolet-B radiation under field conditions in Kunming, Chinese. J. Tropical Agri., 46: 73-76.

Madronich, S., R.L. Mckenzie, M. M. Caldwell and L.O. Bjorn, 1995. Changes in ultraviolet radiation reaching the Earth's surface. Ambio, 24: 143-153.

Miflin, B.J. and P.J. Lea, 1980. Ammonia Assimilation. In: The Biochemistry of Plants, Comprehensive Treatise. Amino Acids and Derivatives A, Miflin, B.J. (Ed.), Academic Press, New York, pp: 169-202.

Moody, S.A., N.D. Paul, L.O. Bjorn, T.V. Callaghan and J.A. Lee et al., 2001. The direct effects of UV-B radiation on Betula pubescens litter decomposing at four European field sites. Plant Ecol., 154: 27-36. DOI: $10.1023 / \mathrm{A}: 1012965610170$

Moore, S., 1968. Amino acid analysis: Aqueous dimethyl sulfoxide as solvent for ninhydrin reaction. J. Biol. Chem., 243: 6281-6283. PMID: 5723468

Niu, C.P., J.Y. Jiang and Y. Huang, 2007. Influence of increased UV-B radiation on $\mathrm{C}$ and $\mathrm{N}$ metabolism of winter wheat. J. Agro-Environ. Sci., 26: 1327-1332. 
Paponov, I. and C. Engels, 2003. Effects of nitrogen supply on leaf traits related to photosynthesis during grain filling in two maize genotypes with different $\mathrm{N}$ efficiency. J. Plant Nutr. Soil Sci., 166: 756-763. DOI: $10.1002 /$ jpln.200320339

Peng, Q. and Q. Zhou, 2010. Effects of enhanced UV-B radiation on the distribution of mineral elements in soybean (Glycine max) seedling. Chemosphere, 78: 859-863. DOI: 10.1016/j.chemosphere.2009.11.050

Rajendiran, K. and M.P. Ramanujam, 2006. Interactive effects of UV-B irradiation and triadimefon on nodulation and nitrogen metabolism in Vigna radiata plants. Biol. Plant, 50: 709-712. DOI: 10.1007/s10535-006-0112-3

Reifenrath, K. and C. Muller, 2007. Species-specific and leaf-age dependent effects of ultraviolet radiation on two brassicaceae. Phytochem., 68: 875-885. DOI: 10.1016/j.phytochem.2006.12.008

Roblek, M., M. Germ, T.T. Sedej and A. Gaberščik, 2008. Morphological and biochemical variations in St. John's wort, Hypericum perforatum L., growing over altitudinal and UV-B radiation gradients. Period Biol., 110: 257-262.

Sangtarash, M.H., M.M. Qaderi, C.C. Chinnappa and D.M. Reid, 2009. Differential sensitivity of canola (Brassica napus) seedlings to ultraviolet-B radiation, water stress and abscisic acid. Environ. Exp. Biol., 66: 212-219. DOI: 10.1016/j.envexpbot.2009.03.004

Sullivan, J. H. and A.H. Teramura, 1990. Field study of the interaction between solar ultraviolet-B radiation and drought on photosynthesis and growth in soybean. Plant Physiol., 92: 141-146. DOI: 10.1104/pp.92.1.141

Sullivan, J.H., 2005. Possible impacts of changes in UV$\mathrm{B}$ radiation on North American trees and forests. Environ. Pollut., 137: 380-387. DOI: 10.1016/j.envpol.2005.01.029

Tang, Z.C., 1999. Experimental Guide to Modern Plant Physiology. 1st Edn., Science Press, Beijing.

Tevini, M., J. Braun and G. Fieser, 1990. The protective function of the epidermal layer of rye seedlings against ultraviolet-B radiation. Photochem. Photobiol., 53: 329-333. DOI: 10.1111/j.17511097.1991.tb03636.x

Turunen, M. and K. Latola, 2005. UV-B radiation and acclimation in timberline plants. Environ. Pollut., 137: 390-403. DOI: 10.1016/j.envpol.2005.01.030

Watanabe, S., T. Takemura, K. Sudo, T. Yokohata and H. Kawase, 2012. Anthropogenic changes in the surface all-sky UV-B radiation through 1850-2005 simulated by an Earth system model. Atmospheric Chem. Phys., 12: 4221-4242. DOI: 10.5194/acp-125249-2012
Weatherhead, B., A. Tanskanen and A. Stevermer, 2005. Ozone and Ultraviolet Radiation. In: Arctic Climate Impact Assessment Scientific Report, Symon, C., L. Arris and B. Heal (Eds.), Cambridge University Press, New York, pp: 151-182.

Wu, X.C., C.X. Fang, J.Y. Chen, Q.S. Wang and T. Chen et al., 2011. A proteomic analysis of leaf responses to enhanced ultraviolet-B radiation in two rice (Oryza sativa L.) cultivars differing in UV sensitivity. J. Plant Biol., 54: 251-261. DOI: 10.1007/s12374-011-9162-y

$\mathrm{Xu}$, C.N., S. Savithiry and H. Joe, 2008. Impact of solar ultraviolet-B radiation on the antioxidant defense system in soybean lines differing in flavonoid contents. Environ. Exp. Bot., 63: 39-48. DOI: 10.1016/j.envexpbot.2007.10.029

Xu, Z.Z. and G.S. Zhou, 2007. Relationship between carbon and nitrogen and environmental regulation in plants under global change-from molecule to ecosystem. J. Plant Ecol., 31: 738-747.

Yang, Y.Q., Y.A. Yao and H. He, 2008. Influence of ambient and enhanced ultraviolet-B radiation on the plant growth and physiological properties in two contrasting populations of Hippophae rhamnoides. Plant Res., 121: 377-385. DOI: 10.1007/s10265008-0163-y

Yao, X. and Q. Liu, 2007. Responses in growth, physiology and nitrogen nutrition of dragon spruce (Picea asperata) seedlings of different ages to enhanced ultraviolet-B. Acta Physiol. Plant, 29: 217224. DOI: $10.1007 / \mathrm{s} 11738-007-0027-4$

Zu, Y.Q., L.F. Wei, J.L. Yang and Y. Li, 2005. Effects of UV-B radiation on population dynamics and diversity of 40 wild sugarcane (Saccharum spontaneum L.) clones rhizosphere microorganisms. J. Agro-Environ. Sci., 24: 6-11.

Zu, Y.Q., Y. Li, L. Qin, Y.M. He and H.Y. Wang et al., 2007. Effects of enhanced UV-B radiation on plant height and stem diameter of wild sugarcane (Saccharum spontaneum L.) clones for three consecutive years. J. Agro-Environ. Sci., 26: 503508 . 